\title{
Single Center Study on Clinical Features of 595 Behçet's Disease Patients in Turkey
} F Topaloglu Demir ${ }^{1}$, O Yontem ${ }^{1}$, E Dervis ${ }^{1}, \mathrm{~K} \mathrm{Koc}^{1}$, OY Hacımustafaoglu ${ }^{1}$, M Demir ${ }^{2}, \mathrm{Z}$ Turkoglu ${ }^{1}$

\begin{abstract}
Objective: We aimed to evaluate the clinical spectrum of Behçet's disease in both pediatric and adult patients, and find out the risk factors for severe organ involvements.

Material and methods: Results of 595 patients diagnosed with Behcet's disease according to International Behcet's Disease Study Group (1990) criterias, admitted to the dermatology department, Behcet's disease polyclinic of Haseki Training and Research Hospital between 1993-2016 years were evaluated.
\end{abstract}

Results: A total of 595 patients with Behçet's disease (305 male, 290 female, 17 children)

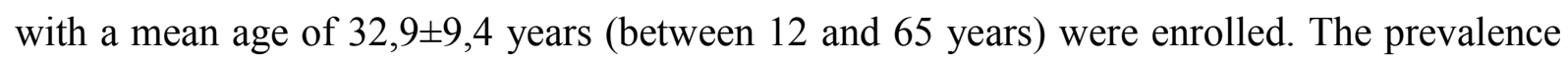
of mucocutaneous lesions and system involvements was as follows: oral aphthae $100 \%$, genital ulcer $83,5 \%$, papulopustular lesions $56,8 \%$, erythema nodosum $37,5 \%$, pathergy positivity 45,2\%, articular involvement $67,7 \%$, eye involvement $18,9 \%$, vascular involvement $6,7 \%$, neurologic involvement $1,5 \%$ and gastrointestinal system involvement 0,2 $\%$. While papulopustular lesions, pathergy positivity and vascular involvement were found more frequently in males, eritema nodosum was more common in females. Neurological involvement was significantly more frequent in patients with ocular involvement $(p=0,014)$. Genital ulcer, skin findings, articular and ocular involvement were detected less frequent in patients with positive pathergy reaction. Clinical features of children were similar to the adults.

Conclusion: Ocular involvement in Behçet's patients may be a predictor for other serious organ involvements. While pathergy positivity was evaluated as a good prognostic factor, male gender was associated with a poor prognosis.

Keywords: Behçet's disease, clinical features, prognostic factors, Turkey

From: ${ }^{1}$ Department of Dermatology, Haseki Training and Research Hospital, Istanbul, Turkey.

${ }^{2}$ Department of Ophthalmology, Okmeydanı Training and Research Hospital, Istanbul, Turkey.

Correspondence: Dr F Topaloğlu Demir, Department of Dermatology, Haseki Training and Research Hospital, 34096, Istanbul, Turkey. Fax: +90 21258962 29, e-mail: filizsvet@yahoo.com 


\section{INTRODUCTION}

Behçet's disease (BD), which was first defined and named by Hulusi Behçet, a Turkish Professor of Dermatology, in 1937, is a chronic, multisystem inflammatory disease characterized by oral aphthae, genital ulcers, cutaneous lesions, and articular, ocular, vascular, neurologic and gastrointestinal system involvements $(1,2)$. The prevalence of BD is higher in countries lying along the ancient Silk Road, from the eastern Mediterranean to East Asia. Epidemiologic studies have reported that BD has most prevalently seen in Turkey $(3,4)$. The frequency of BD in Turkey has been reported to range from 2 to 42 cases per $10.000(4,5)$. The natural course of BD is not fully understood yet. Mucocutaneous findings and systemic involvements rates show regional differences within a country and between countries. The information is also limited in pediatric group. In this study we aimed to evaluate the clinical spectrum of BD in both pediatric and adult patients, and determine the risk factors for severe organ involvements.

\section{MATERIAL AND METHODS}

During the years 1993 through 2016, in total, 595 patients (290 female and 305 male) who attended the BD units of Haseki Training and Research Hospital were involved in the study. The diagnostic criteria of the International Study Group of Behçet's Disease was used for he diagnosis of $\mathrm{BD}$ (6). We retrospectively evaluated our Behçet's patients in terms of demographic characteristics, oral aphthae, genital ulcers, skin findings like erythema nodosum, and papulopustular lesions, other organ involvements and pathergy test positivity. And we compared the prevalence of mucocutaneous manifestations and systemic findings of 595 Behçet's patients according to sex and age statistically. Patients were divided into two 
groups according to age: group 1, pediatric patients, $<18$ age and group 2, adult patients, $\geq 18$ age. The clinical data of patients were obtained from patient charts.

\section{Statistical analysis}

For statistical analysis, we used SPSS 15.0 for Windows. Descriptive statistics; numbers and percentages for categorical variables, the mean and standard deviation for continuous variables, minimum, maximum and median were given. Mann Whitney $U$ test was performed when two independent groups comparison did not provide numerical variable normal contribution condition. Chi-square analysis was used to evaluate the independent group rates. In the absence of the required conditions Monte Carlo simulation was performed. Statistical significance of alpha level was considered as $\mathrm{p}<0.05$.

\section{RESULTS}

Of the 595 Behçet patients, 305 patients $(51,3 \%)$ were male and 290 patients $(48,7 \%)$ were female. The male/female ratio was 1,1 . The patients were from 12 to 65 years of age (mean age $32,9 \pm 9,4$ years). Seventeen patients $(2,9 \%)$ were under 18 years old. Pediatric patients mean age was detected as $15,9 \pm 1,2$ years (range: 12 to 17 ). ). The average follow-up period was $45,0 \pm 31,2$ months (range: 1 to 146 ).

Among mucocutaneous lesions, oral aphthae was detected in all patients. Genital ulcer was found in 497 patients $(83,5 \%)$. Out of these patients, 254 patients were male, 243 patients were female. Genital ulcer was found in $83,3 \%$ male patients and $83,8 \%$ of female patients. The difference between male and female patients was not statistically significant ( $p$ $>0.05)$. (Table 1) 
Papulopustular lesions were seen in 338 patients $(56,8 \%)$ Of these patients 192 were male ( $63 \%$ of male patients $)$ and 146 were female $(50,3 \%$ of female patients). The prevalence of papulopustular lesions was found to be higher in males $((\mathrm{p}=0,002)$ (Table 1$)$.

Erythema nodosum occured in 223 patients (37,5\%). It was present in $31,1 \%$ of male patients (95 patients) and 44,1 \% of female patients (128 patients). Erythema nodosum was significantly more often in females than in males $(p=0.001)$ (Table 1). Skin lesions included erythema nodosum and papulopustular lesions were present in 446 patients (75\%). All of the patients had mucocutaneous lesions.

Articular involvement was observed in 403 patients $(67,7 \%)$. Arthritis was noted in 49 patients $(8,2 \%)$ and 354 patients $(59,5 \%)$ had arthralgia. Out of these patients, 199 were male $(65,2 \%$ of male patients) and 204 were female ( 70,3\% of female patients). The sex difference was not statistically significant for articular involvement $(\mathrm{p}>0.05)$ (Table 1).

Ocular involvement was present in 112 patients (18,9\%). Sixty one were male $(20 \%$ of male patients) and 51 patients were female (17,6\% of female patients). The sex difference for ocular involvement was not statistically significant $(\mathrm{p}>0.05)$ (Table 1). Genital ulcer was seen in $70,5 \%$ of patients with ocular involvement and this ratio was $86,5 \%$ in patients without ocular involvement. Genital ulcers were detected significantly less in patients with ocular involvement $(\mathrm{p}<0,001)$. While neurologic involvement was detected in $4,5 \%$ of patients with ocular involvement, this ratio was found in $\% 0,8$ of patients without neurologic involvement. Neurological involvement was significantly more frequent in patients with ocular involvement $(\mathrm{p}=0,014)$. (Table 2$)$.

Vascular involvement was found in 40 patients $(6,7 \%), 31$ of patients $(77,5 \%)$ had superficial thrombophlebitis and nine of them $(\% 22,5)$ had deep vein thrombosis. Out of these patients, 30 were male $(9,8 \%$ of male patients) and ten were female $(3,4 \%$ of female patients). The prevalence of vascular involvement was higher in males $(p=0,002)$ (Table 1$)$. 
Neurologic involvement was observed in nine patients $(1,5 \%)$. Five of them were male $(1,6$ $\%$ of male patients) and four of them were female (1,4\% of female patients). The difference was not statistically significant $(\mathrm{p}>0.05)$ (Table 1$)$. Gastrointestinal system involvement was seen in only one patient $(0,2 \%)$.

Positive pathergy reaction was detected in 269 patients $(45,2 \%) ; 160$ of these patients $(52,5 \%)$ were male and 109 of them $(37,6 \%)$ were female. Pathergy positivity was significantly more often in males than in females $(p<0,001)$ (Table 1$)$. When we compared mucocutaneous findings and systemic manifestations with pathergy positivity, we found that genital ulcer, skin findings, articular and ocular involvement were less frequent in patients with positive pathergy reaction $(\mathrm{p}=0,031, \mathrm{p}=0,005, \mathrm{p}<0,001$, and $\mathrm{p}=0,042$, respectively). (Table 3)

In pediatric patients oral aphthae was also detected in all patients, Genital ulcer was found in 14 patients $(82,4 \%)$, papulopustular lesions were seen in six patients $(35,3 \%)$, and erythema nodosum occured in three patients $(17,6 \%)$. Articular involvement was present in 10 patients $(58,8 \%)$. Ocular involvement was found in five patients $(29,4 \%)$. Only one patient $(5,9 \%)$ had vascular involvement. There was no statistically difference between pediatric and adult patients in terms of mucocutaneous findings, pathergy positivity and systemic manifestations $(\mathrm{p}>0,05)$ (Table 4$)$.

\section{DISCUSSION}

BD is usually observed in young people between 20 and 40 years of age, but rarely in children $(7,8)$. It has been reported to be equal in male and female patients (9). The male/female ratio was reported as 1.03 in the study of Tursen and colleagues, this ratio was 1.1 in our study (10). The mean age of all patients was found $32.9 \pm 9.4$ years and it was 
correlated with studies performed in our country (10). It has been reported that BD has had more severe clinical course in men and early onset patients $(2,10)$. The prevalence of folliculitis, thrombophlebitis, ocular involvement and joint involvement were reported to be higher in male patients than in females by Yazic1 et al. (2). Tursen et al. reported that papulopustular lesions, ocular, vascular, neurologic and pulmonar system involvements were more common in men and genital ulcers and erythema nodosum were more common in women (10). Genital ulcers, papulopustular lesions, thrombophlebitis, and ocular involvement were found to be more frequent in male patients in Alpsoy et al.'s study (11). In our study, correlated to the literature, papulopustular lesions and vascular involvement were more frequent in male patients and erythema nodosum was more common in females. Different from the literature, there were no differences between genders in terms of genital ulcers, ocular and neurological involvement.

Skin and mucosal findings are the most frequent symptoms at the beginning or any period of the disease and extremely important in the early diagnosis $(1,12)$. It has been reported in literature that $92-100 \%$ of patients have oral aphthae, $57-93 \%$ of patients have genital ulcers and $38-99 \%$ of patients have skin symptoms. Erythema nodosum $(15-78 \%$ of patients) and papulopustular lesions ( $28-96 \%$ of patients ) are the most commonly seen skin findings. (12-14). The ratio of oral aphthae was reported as $100 \%$, genital ulcer was observed in $88,1 \%$ of patients, papulopustular lesions were found in $54 \%$ of patients and erythema nodosum was reported in $47,6 \%$ of patients in the study of Tursen et al.(10) In the multicenter study of Alpsoy et al., oral aphthae was seen in all patients, genital ulcer was seen in $85,3 \%$, papulopustular lesions were seen in $55,4 \%$ and erythema nodosum was seen in $44,7 \%$ of patients (11). Mucocutaneous BD was present in all our patients. In our study, the prevalence of oral aphtae (100\%), genital ulcer $(83,5 \%)$ and papulopustular lesions $(56,8 \%)$ 
were found correlated with the literature but the frequency of erithema nodosum was found less frequent according to Tursen et al's and Alpsoy et al's studies $(10,11)$.

After the mucocutaneous findings, ocular (29-100\%) and articular involvement (16$84 \%$ ) have been reported be the most commonly seen systemic involvements as it was in our study. (12,14). The prevalence of patients with ocular involvement have been reported in different rates in previous reports from our country. Ocular involvement in BD was reported by Gürler et al. as 28,9\% (15), Tursen et al. as 29,1\% (10), Gündüz et al. as $40 \%$ (16) and Karabacak et al. as $52,7 \%$ (17). When we compared our results to the literature the prevalence of ocular involvement was lower (18.9\%). Also different from the literature neurologic involvement was most commonly seen in patients with ocular involvement. Ocular involvement may be a predictor for other serious organ involvements.

Vascular involvement has been reported at rates ranging from $1.8 \%$ to $57,1 \%$ in patients with BD. Koç et al indicated that venous system involvement (88\%) was the main involvement area of the disease in their study. The most common form of venous involvement was reported as superficial thrombophlebitis (47.3\%). In our study, vascular involvement was present in $6.7 \%$ of patients. Correlated with the literature superficial thrombophlebitis $(77.5 \%)$ was the most commonly seen form of vascular involvement (18).

In previous reports the prevalence of neurologic involvement has been reported to be between $2.2 \%$ and $50 \%$ (19). The prevalence of neurologic involvement has been reported as $5-7 \%$ in the studies from our country (20). In this study, neurologic involvement was found in $1.5 \%$ of patients, and this rate was lower than the literature .

Although different results have been reported in the literature related to the gastrointestinal system involvement in Behçet's disease, correlated to our study, the prevalence in Turkey and Israel has been reported at low rates $(0-5 \%)(21,22)$. 
Positivity of pathergy test has been found to be between $6 \%$ to $71 \%$ of Behçet's patients. (12). Pathergy test results were also varied in previous studies from Turkey between $8 \%$ to $57,3 \%(17,23)$. While Tursen et al.(10), Azizlerli et al.(4) and Gündüz et al. (16) were detected no differences between two sexes in regard to pathergy positivity, Yazıcı et al., Alpsoy et al and Allı et al. were reported that pathergy positivity was significantly higher in male patients as it was in this study $(11,24,25)$. Krause et al. reported lack of correlation with pathergy positivity to mucocutaneous manifestations and systemic involvements (26). Unlike the literature negative correlation was detected between pathergy positivity and genital ulcers, skin findings, ocular and articular involvements. Pathergy positivity may be a good prognostic marker.

Behçet's disease begins during childhood about 2-3\% of cases (27). Correlated with the literature $2,9 \%$ of patients were children in this study. Clinical features of children were similar to the adults as Borlu et al 's study (8). We found the prevalence of genital ulcer, papulopustular lesions, articular involvement and pathergy positivity lower, ocular involvement higher than Borlu et al's study. Different from Borlu et. al's study no neurologic and gastrointestinal system involvement was detected and thrombophlebitis was found in one patient (8). Karıncaoğlu et al. compared the clinical manifestations in children to adults and consistent to our study mucocutaneous lesions and articular involvement were the most commonly seen clinical manifestations. Unlike our study neurological involvement and gastrointestinal involvement in juvenile cases were determined more than in adults (28). 


\title{
CONCLUSION
}

Articular and ocular involvement are the most commonly seen systemic involvements outside the mucocutaneous findings. Papulopustular lesions, vascular involvement and pathergy test positivity are more common in males, erythema nodosum is more frequent in females.

Because vascular involvement is more common in men, male gender is associated with poor prognosis. While ocular involvement in Behçet's patients may be a predictor for other serious organ involvements, pathergy positivity may be a good prognostic factor. Ocular and neurologic involvement rates are significantly low in this study. We believe that beyond the ethnic and regional differences, early initiation and prolonged usage of colchicine prevent serious organ involvements in Behçet's disease as Dilsen et al. reported (21).

\begin{abstract}
AUTHORS' NOTE
F Topaloglu Demir conceived oversaw paper, oversaw data collection, conducted data analysis, wrote manuscript and approved final version. O Yontem participated in study design, data analysis and interpretation of data and approved final version. E Dervis, K Koc, OY Hacimustafaoglu and M Demir participated in data collection, interpretation of data and approved final version. Z Turkoglu participated in study design and interpretation of data; critically revised manuscript and approved final version. The authors declare that they have no conflicts of interest.
\end{abstract}




\section{REFERENCES}

1. Behcet $\mathrm{H}$ : Über rezidiverende, aphtöse durch ein Virus verursachte Geschwüre am Mund, am Auge, und den Genitalien. Dermatol Wochenschr 1937; 105: 1152-7.

2. Yazici H, Tüzün Y, Pazarli H, Yurdakul S, Ozyazgan Y, Ozdoğan H, et al. Influence of age of onset and patient's sex on the prevalence and severity of manifestations of Behçet's syndrome. Ann Rheum Dis. 1984; 43: 783-9.

3. Yurdakul S: Behçet sendromunun epidemiyolojisi. Aktüel Tıp Dergisi 1997; 2: 66-7.

4. Azizlerli G, Köse AA, Sarica R, Gül A, Tutkun IT, Kulaç M, et al. Prevalence of Behçet's disease in Istanbul, Turkey. Int J Dermatol. 2003; 42: 803-6.

5. Cakir N, Dervis E, Benian O, Pamuk ON, Sonmezates N, Rahimoglu R, et al. Prevalence of Behçet's disease in rural western Turkey: a preliminary report. Clin Exp Rheumatol. 2004; 22: 53-55.

6. The International Study Group for Behçet's Disease. Evaluation of diagnostic (“classification”) criteria in Behçet's Disease: towards internationally agreed criteria. Br J Rheumatol 1992; 31: 299-308.

7. Wong RC, Ellis CN, Diaz LA. Behcet's disease. Int J Dermatol 1984;23:25-32.

8. Borlu M, Ukflal U, Ferahbafl A, Evereklioglu C: Clinical features of Behcet's disease in children. Int J Dermatol 2006; 46; 713-6.

9. Gharibdoost F, Davatchi F, Shahram F, Akbarian M, Chams C,. Chams H, et al. Clinical Manifestations of Behçet's Disease in Iran Analysis of 2176 cases. In: Godeau P, Wechsler B, eds. Behçet's Disease. Amsterdam: Elsevier Science Publishers, 1993: $153-158$.

10. Tursen U, Gurler A, Boyvat A. Evaluation of clinical findings according to sex in 2313 Turkish patients with Behcet's disease. Int J Dermatol. 2003; 42: 346-51. 
11. Alpsoy E, Donmez E, Onder M, Gunasti S, Usta A, Karincaoglu Y, et al. Clinical features and natural course of Behcet's disease in 661 cases: a multicenter study. Br J Dermatol 2007; 157: 901-6.

12. Zouboulis CC. Epidemiology of Adamantiades-Behcet's disease. Ann Med Interne 1999; 150: 488-498.

13. Alpsoy E, Aktekin M, Er H, Durusoy C, Yilmaz E. Distribution and frequency of papulopustular lesions in Behçet's disease: A randomized,controlled study. Int J Dermatol. 1998; 37: 839-843.

14. Alpsoy E, Dönmez L, Bacanlı A, Apaydin C, Butun B. Review of the clinical manifestations' chronology in 60 patients with Behçet's disease. 10th International Conference on Behçet's disease; Berlin-Germany, 27-29 June 2002.

15. Gürler A. Boyvat A and Türsen Ü. Clinical manifestations of BehÇet's disease: an analysis of 2147 patients. Yonsei Med J. 1997; 38: 423-427.

16. Gündüz Ö, Gürler A, Tuğrul Ayanoğlu B, Erdoğan FG, Alhan A. Epidemiological Properties of Behçet's Disease Patients Who Had Been Followed Up at Behçet's Disease Center. Turkiye Klinikleri J Dermatol 2015; 25: 85-91.

17. Karabacak E, Aydın E, Doğan B, Tekeli H, Tekin L, Göker K, et al. Behçet's disease: The clinical and demographic characteristics of 182 patients. Turkderm. 2014; 48: $121-26$.

18. Koc Y, Gullu I, Akpek G, Akpolat T, Kansu E, Kiraz S, et al. Vascular involvement in Behcet's disease. J Rheumatol 1992; 19: 402-10.

19. Al-Araji A, Sharquie K, Al-Rawi Z: Prevalence and pattern of neurological involvement in Behcet's disease: a prospective study from Iraq. J Neurol Neurosurg Psychiatry 2003; 7: 608-13. 
20. Akman-Demir G: Behçet Hastalığında Nörolojik Tutulum. Turkderm 2009; 43 Özel Say1: 61-4.

21. Dilşen N, Konige M, Aral O, Öcal L, Inang M, Gill A. Risk factors in vital organ involvement in Behçet's disease. In: Wechsler B, Godeau P (eds) Behçet's disease. Elsevier Science Publishers, Amsterdam, 1993, 165-170.

22. Chajek T, Fainaru M. Behçet's Disease: report of 41 cases and review of the literature. Medicine 1975; 54: 179.

23. Dogan B, Taskapan O, Harmanyeri Y: Prevalance of pathergy test positivity in Behçet's disease in Turkey. J Eur Acad Dermatol Venereol 2003; 17: 228-9.

24. Yazici H, Tüzün Y, Tanman AB, Yurdakul S,Serdaroglu S, Pazarli H, et al. Male patients with Behçet's syndrome have stronger pathergy reactions. Clin Exp Rheumatol 1985; 3: 137-41.

25. Alli N, Gur G, Yalcin B, Hayran M. Patient characteristics in Behçet disease: a retrospective analysis of 213 Turkish patients during 2001-4. Am J Clin Dermatol 2009; 10: 411-8.

26. Krause I, Molad Y, Mitrani M, Weinberger A. Pathergy reaction in Behçet's disease: lack of correlation with mucocutaneous manifestations and systemic disease expression. Clin Exp Rheumatol. 2000; 18: 71-4.

27. Saylan T, Mat C, Fresko I, Melikoğlu M. Behcet's disease in The Middle East. Clin Dermatol 1999; 17: 209-22.

28. Karincaoglu Y, Borlu M, Toker SC, Akman A, Onder M, Gunasti S, et al. Demographic and clinical properties of juvenile-onset Behcet's disease: A controlled multicenter study. J Am Acad Dermatol 2008; 58: 579-84. 
Table 1: Clinical manifestations of patients with Behçet's disease according to sex distrinbution

\section{Behçet's Disease}

Female Male

Patients

Age

Oral aphthae

Genital ulcer

Erythema nodosum

Papulopustular lesions

Skin findings

Pathergy positivity

Articular involvement

Eye involvement

Vascular involvement

Neurologic involvement

Gastrointestinal system involvement n $\quad \% \quad$ n $\% \quad p^{*}$

$290 \quad 48,7 \quad 305 \quad 51,3$

$33,4 \pm 10,1 \quad 32,5 \pm 9,7 \quad 0,434$

$\begin{array}{llll}290 & 100 & 305 & 100\end{array}$

$243 \quad 83,8 \quad 254 \quad 83,3 \quad 0,866$

$128 \quad 44,1 \quad 95 \quad 31,1 \quad \mathbf{0 , 0 0 1}$

$146 \quad 50,3 \quad 192 \quad 63,0 \quad \mathbf{0 , 0 0 2}$

$222 \quad 76,6 \quad 224 \quad 73,4 \quad 0,382$

$\begin{array}{lllll}109 & 37,6 & 160 & 52,5 & <\mathbf{0 , 0 0 1}\end{array}$

$204 \quad 70,3 \quad 199 \quad 65,2 \quad 0,184$

$51 \quad 17,6 \quad 61 \quad 20,0 \quad 0,452$

$\begin{array}{lllll}10 & 3,4 & 30 & 9,8 & \mathbf{0 , 0 0 2}\end{array}$

$\begin{array}{lllll}4 & 1,4 & 5 & 1,6 & 1,000\end{array}$

$1 \quad 0,3 \quad 0 \quad 0,0 \quad 0,487$

${ }^{*} \mathrm{p}<0,05$ 
Table 2: The comparison of ocular involvement to mucocutaneous findings and systemic involvements in Behçet's patients

\section{Ocular involvement}

\begin{tabular}{|c|c|c|c|c|c|}
\hline & \multicolumn{2}{|c|}{ No } & \multicolumn{2}{|c|}{ Yes } & \multirow[b]{2}{*}{$\mathrm{p}^{*}$} \\
\hline & $\mathbf{n}$ & $\%$ & $\mathbf{n}$ & $\%$ & \\
\hline Patients & 483 & 81,2 & 112 & 18,9 & \\
\hline Oral aphthae & 483 & 100 & 112 & 100 & - \\
\hline Genital ulcer & 418 & 86,5 & 79 & 70,5 & $<0,001$ \\
\hline Erythema nodosum & 177 & 36,6 & 46 & 41,1 & 0,383 \\
\hline Papulopustular lesions & 280 & 58,0 & 58 & 51,8 & 0,234 \\
\hline Skin findings & 366 & 75,8 & 80 & 71,4 & 0,339 \\
\hline Articular involvement & 331 & 68,5 & 72 & 64,3 & 0,387 \\
\hline Vascular involvement & 33 & 6,8 & 7 & 6,3 & 0825 \\
\hline $\begin{array}{l}\text { Neurologic } \\
\text { involvement }\end{array}$ & 4 & 0,8 & 5 & 4,5 & 0,014 \\
\hline $\begin{array}{l}\text { Gastrointestinal } \\
\text { system involvement }\end{array}$ & 1 & 0,2 & 0 & 0,0 & 1,000 \\
\hline
\end{tabular}

$*_{\mathrm{p}}<0,05$ 
Table 3: The comparison of pathergy reaction to mucocutaneous findings and systemic involvements

\section{Pathergy reaction}

Patients

Oral aphthae

Genital ulcer

Erythema nodosum

Papulopustular lesions

Skin findings

Articular involvement

Ocular involvement

Vascular involvement

Neurologic

involvement

Gastrointestinal system

involvement

$* p<0.05$
Negative

n $\quad \%$

$\begin{array}{llll}326 & 54,8 & 269 & 45,2\end{array}$

\section{Positive}

$\begin{array}{llll}326 & 100 & 269 & 100\end{array}$

$282 \quad 86,5 \quad 215 \quad 79,9 \quad \mathbf{0 , 0 3 1}$

$\begin{array}{lllll}130 & 39,9 & 93 & 34,6 & 0,183\end{array}$

$190 \quad 58,3 \quad 148 \quad 55,0 \quad 0,424$

$259 \quad 79,4 \quad 187 \quad 69,5 \quad \mathbf{0 , 0 0 5}$

$245 \quad 75,2 \quad 158 \quad 58,7 \quad<\mathbf{0 , 0 0 1}$

$\begin{array}{lllll}71 & 21,8 & 41 & 15,2 & \mathbf{0 , 0 4 2}\end{array}$

$\begin{array}{lllll}17 & 5,2 & 23 & 8,6 & 0,106\end{array}$

$\begin{array}{lllll}6 & 1,8 & 3 & 1,1 & 0,523\end{array}$

$\begin{array}{lllll}1 & 0,3 & 0 & 0,0 & 1,000\end{array}$ 
Table 4: Clinical manifestations of patients with Behçet's disease according to age

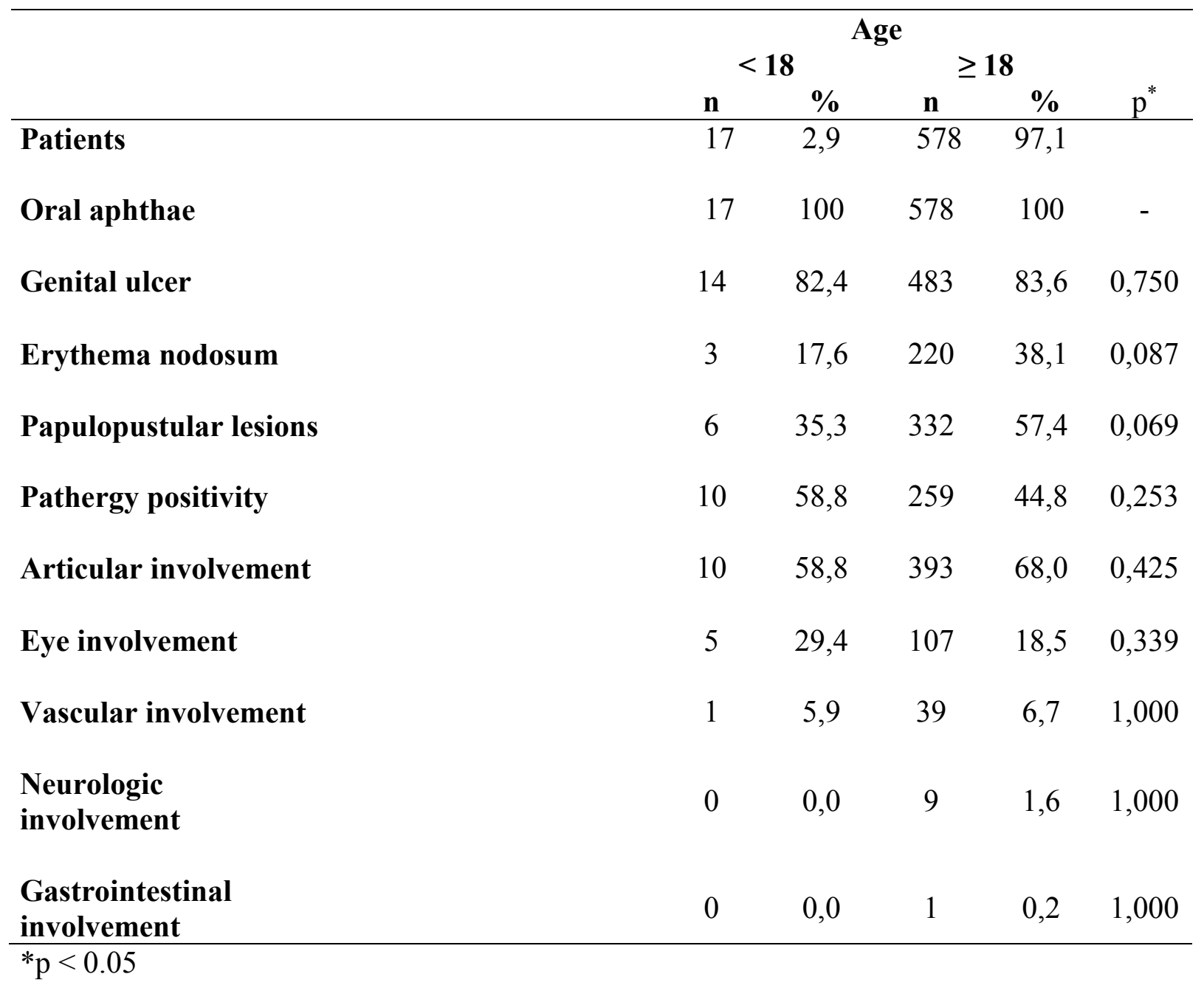

